\title{
NOTA DE CORRECCION
}

Erratas del artículo Existencia de juegos diferenciales con valor dado de Procopio Zoroa Terol, publicado en el volumen XX, Cuadernos 2 y 3 de esta Revista.

\begin{tabular}{|c|c|c|c|}
\hline Página & Línea & Dice & Debe decir \\
\hline 83 & 7 & aproximadamente & apropiadamente \\
\hline 88 & 18 & terminar por & terminar en \\
\hline 90 & 12 & $a_{i j}<0$ & $a_{1 i}<0$ \\
\hline 90 & -9 & lo & la \\
\hline 91 & -6 & $x_{p}$ & $x_{P}$ \\
\hline 91 & -4 & $x_{p}$ & $x_{P}$ \\
\hline 91 & -2 & $x_{p}$ & $x_{P}$ \\
\hline 101 & -10 & $0 a_{p 1} a_{p 2} \ldots a_{p m}$ & $0 a_{p 2} a_{p 3} \ldots a_{p m}$ \\
\hline 102 & 2 & $\frac{l}{l+D}$ & $\frac{\varphi_{1}}{1+D}$ \\
\hline 102 & 3 & $\frac{2}{1+D}$ & $\frac{\varphi_{2}}{l+D}$ \\
\hline 102 & 5 & $\frac{p}{l+D}$ & $\frac{\varphi_{p}}{1+D}$ \\
\hline $\begin{array}{l}102 \\
104\end{array}$ & $\begin{array}{l}-1 \\
10\end{array}$ & $\begin{array}{l}=M\left(\bar{\varphi}^{(i)}, \bar{\psi}\right)= \\
\text { juego }\end{array}$ & $\begin{array}{l}\leqslant M\left(\bar{\varphi}^{(i)}, \bar{\psi}\right) \leqslant \\
\text { pago }\end{array}$ \\
\hline 106 & $\begin{array}{r}\text { entre } 2 \\
\text { Tra }\end{array}$ & $\begin{array}{l}\text { y } 3 \text { falta lo siguiente: } \\
\text { yectorias óptimas } \\
\qquad \frac{x_{2}}{x_{1}+1}=\text { con }\end{array}$ & ante \\
\hline
\end{tabular}

1096 Funciones cinemáticas Ecuaciones cinemáticas

10911 que el ejemplo que en el ejemplo

$\begin{array}{llll}112 & -17 & G(x, \varphi)> & G(x, \varphi)>0\end{array}$

$112 \quad-16 \quad S \cap T \neq \Phi \quad S \cap T \neq \phi$ 


$\begin{array}{ccll}112 & -10 & \min H(s)=H\left(s^{\prime}\right) & \min H(s)=H\left(s^{\prime}\right) \\ & & & g(s) \in T \\ 112 & -8 & g\left(s^{\prime}\right) \in S \cap T g(s) \in T & g\left(s^{\prime}\right) \in S \cap T \\ 113 & 9 & \text { que coincide } & \text { que coincide con } \\ 115 & 11 & \text { en el normal } & \text { es el normal } \\ 115 & -11 & \text { por capricho } & \text { a capricho }\end{array}$

